\title{
Social Cohesion in the Time of Crisis: An Empirical Research on EU Member States
}

\author{
By Felice Addeo* \\ Paolo Diana ${ }^{\dagger}$ \\ Gianmaria Bottoni \\ Maria Esposito ${ }^{+}$
}

The sociological concept of Social Cohesion, after a first stage in which it gained spread and notoriety within social sciences, has been abandoned in favor of other similar concepts, such as integration and solidarity. However, during the last twenty years, the concept has regained relevance mainly thanks to the intervention of several institutions, both national and international (OECD, EU, World Bank, Governments of some countries, such as England, France and Canada), that have reconsidered the concept of Social Cohesion, adapting it to their governance needs. The present work aims at proposing an effective and reliable theoretical and operational definition for the concept of Social Cohesion, starting from the contribution of those scholars (Stiglitz, Sen and Fitoussi 2009) that claimed the inadequacy of measuring the welfare of a country only through economic indicators. In other words, the aim of this contribution is to provide a concept of Social Cohesion that will take into account not only economic factors, but also other fundamental dimensions that define the Welfare of a country, such as active citizenship, trust, shared values and integration. The concept of Social Cohesion is defined with the aid of several databases (Eurostat, but also academic datasets) from which different socio-economic indicators for the $27 \mathrm{EU}$ Member States will be drawn. Data are analyzed through an explorative factor analysis approach, whose main result will be the creation of a Social Cohesion composite index. The Social Cohesion Index will rank the 27 EU Member States. Moreover, the research will consider a comparative analysis among different models of Social Cohesion observed in the European countries, with particular reference to the differences between the States of Southern Europe and those with different welfare systems, typical of Northern Europe.

Keywords: Comparative analysis, Composite indicators, Social cohesion, Two-stage principal component analysis, Welfare.

\section{How to Assess the Well-Being of a Nation: Going Beyond GDP}

Since ancient times, the question about what can make a man feel happy caught the attention of the most important thinkers. From Socrates who identified happiness as the result of an inner virtuous behavior up to the

\footnotetext{
* Assistant Professor, University of Salerno, Italy.

${ }^{\dagger}$ Assistant Professor, University of Salerno, Italy.

$\$$ PhD Candidate, University of Rome, Italy.

${ }^{+}$PhD Candidate, University of Salerno, Italy.
} 
Aristotle's concept of "Eudaimonia" (Diener and Suh 1997), where happiness is the product of a rational inner feeling able to distinguish the "golden middle", otherwise known as aura mediocritas, between two extremes. In the $18^{\text {th }}$ century, the idea of aurea mediocritas stirred also one of the most known statistical breakthroughs, the Normal Curve, whose applications crossed the boundaries of the statistical domain to inspire several social and psychological theories (Addeo 2008).

Even the most recent philosophical reflections dealt with the topics of human needs. One of the most influential contributions comes from the Marxist school; thinkers like Marcuse, Fromm and Heller developed the "Theory of Needs". These authors strongly criticized the capitalist society as it caused several destructive phenomena for humanity: alienation, need of unnecessary things, denial of the "real" needs.

The issue of human needs will be fundamental for all further research: from Maslow and his pyramid of needs, that distinguishes between primary and secondary needs, up to Inglehart (1977) with his distinction between materialistic needs and post materialistic needs. The common thread of these analyses is the distinction between primary or materialistic needs and secondary or post-materialistic needs. Moreover, the concept of well-being is separated from the idea of material possession, getting closer to the concept of "striving for happiness", to be understood as balance, free expression, a convergence between a "lifestyle" and ethical and moral values.

Even within the classical philosophical tradition, there are two distinct paradigms: the first one (expressed, for example, by Sophists, Epicureans, and Cyrenaica School) identifies happiness with material possession or the satisfaction of material needs; the second one considers happiness as something closer to an inner well-being, a state of mind. In this regard, we can recall the Cynics, the Stoics and Roman philosophy. This distinction seems to recall the modern debate about individual well-being, where some scholars identify it with the possession of material resources, while others considering the materialistic dimension just as one of many, including, for example, the quality of social relations, the level of education, the sharing of a common feeling. All these factors would influence the level of the individual well-being.

The well-being of nations and individuals has been conceived in different ways according to several authors and schools of thought. Many economists consider the well-being as the result of material possession (Stiglitz et al. 2009). According to them, GDP is the most used and useful proxy both to measure the policies of a nation and to describe its welfare in a synthetic way. Nowadays, this approach seems to be overly resizing; if we ask people to assess their quality of life, most likely they will consider not only the economic factors, also other elements, such as the possibility to be educated, to grow in a healthy environment, to live in a town without crime. GDP does not take into account these elements and other elements of the social, psychological and cultural sphere.

The gap between macroeconomic performances and the overall well-being of a nation seems evident to most observers, especially considering current 
issues such as the environmental protection, inequalities among citizens or the widespread awareness that an aggressive market economy can produce social malaise. Therefore, in order to measure the well-being of an individual, a society, a country or a supranational aggregation, it is necessary to take into account other elements.

Obviously, the economic proxies, such as wealth, income and consumption are not becoming irrelevant, but it is necessary to integrate them with other indicators. In other words, even if economic resources are important, they are not sufficient for assessing the quality of life and the well-being of a nation.

The reasons of this are manifold. First, the awareness that the economic approach - according to which a change in the level of income or wealth leads to an equal change in the level of well-being - is reductive. Actually, in many cases, the economic growth may show a negative correlation with other important dimensions of the quality of life, such as the individual free time, the water quality, etc.

Moreover, it is possible to notice that the same level of material resources could imply different satisfaction levels, because different people have different needs and, above all, different capabilities in transforming their resources into well-being (Sen 1985).

With the concepts of capabilities and functioning, Sen refers to the different possibilities (i.e., capabilities) for individuals to use their resources in order to achieve the functioning, in terms of doing or being, that best fits with their cultural horizon and their values (Clark 2008).

According to this approach, the availability of goods that it considers is not relevant any more, since this dimension alone does not allow evaluating the well-being of an individual.

Individual satisfaction alone is not a good predictor of quality of life, because a person's satisfaction may be high, but this may be due to their low expectations. According to Sen, in order to evaluate the quality of life, it is necessary to assess what individuals can do with their set of resources and how they convert this set into concrete capacities for action. According to this model, inequalities are not the result of a different distribution of goods among the population, but rather they depend on the different abilities to use the available resources.

Moreover, some important resources for the well-being of every individual (such as the amount of leisure time) are not marketable, and they cannot be evaluated just through economic indicators: for some resources, a market price does not exist and some goods cannot be purchased on the market, such as the public health delivery system. Even when it is possible to set a price, this will vary from one individual to another: two different consumers in fact, could attribute different values to the same good, because they evaluate it differently according to their personal idea of satisfaction.

In assessing the quality of life, some subjective elements come into play, such as the capability, due to personal inclinations and attitudes, to enjoy a good more than an another individual. Many studies have highlighted how similar life circumstances can be evaluated differently by individuals 
(Campbell 1981, Diener and Diener 1995, Diener et al. 1995). In this regard, we can mention the so-called socio-psychological approach whose focus is not on the social itself, but on the individual perception about the social (Di Franco1989). For these authors, objective conditions (as the crime rate, health, etc.) are not as relevant as the experience that an individual can make during their lifetime and the evaluation they provide (Campbell et al. 1976).

All the issues presented so far suggest that the current well-being indicators based on income, wealth and consumption are not sufficient for a proper evaluation of the individual quality of life, but it is necessary to integrate them with non-monetary indicators (Stiglitz et al. 2009).

In recent years, the idea of well-being as a sub-dimension of another broader concept, the "Social Cohesion", has widespread. This broader concept is considered suitable to define what constitutes a good life or a good society (Berger-Schmitt 2002).

In particular, many authors have linked this concept to those of Social Exclusion and Social Capital, considering them tightly interconnected in understanding how to achieve the social order as well as solidarity and social integration.

\section{The Sociological Concept of Social Cohesion}

The sociological concept of social cohesion, after an initial phase of success(consider, for example, the works of Durkheim), has been gradually put aside in social sciences in favor of similar concepts, such as integration (Parsons 1937) or solidarity. However, over the last twenty years, social cohesion has experienced a second youth mainly thanks to many institutions (including the OECD, the European Commission, the French Government, and the Canadian Government) that have revitalized the concept, adapting it to their governance requirements.

From a sociological point of view, this rediscovery can be explained by the phase of social change that Europe and the Western world in general are going through. The times during which Durkheim worked were suffering, in the same way, from profound structural changes, which had marked the transition from a traditional to a modern society. Just as Durkheim wondered what factors might help to keep society cohesive, in the same way, the contemporary institutions and the political world in general have to answer the same question: what factors could prevent a social dissolution.

Durkheim (1893) replied to this question by identifying two different forms of solidarity basing two different types of societies: a traditional one and a modern one. The mechanical solidarity of traditional societies is based on the concept of similarity: society is made up of individuals who share the same value system and the same representations. Organic solidarity, that is fundamental for modern society, is founded on opposition to the similarity, i.e. differentiation. This society is the result of labor division and functions differentiation. In such a system, where individuals have specific and 
interconnected functions, the interdependence generates solidarity or, even, cohesion. In addition, academic scholars have resumed the concept of social cohesion after an intermediate stage in which it had been abandoned. This recovery has been partly triggered by various research projects funded by institutions (such as the Canadian Policy Research Networks). From an operational and conceptual point of view, many authors highlight how the concept of cohesion raises numerous scientific issues (Jenson 1998, Jeannotte 2003, Bernard 1999, Beauvais and Jenson 2002, Berger-Schmitt and Noll 2000, Berger-Schmitt 2002, Noll 2002). Difficulties are both on a conceptual level - different definitions provided by different authors and institutions - both empirically - different operational definitions with too many indicators.

In this regard, Jenson summarizes the epistemological status of the concept of cohesion with these words: "social cohesion is an ambiguous concept because it can be used by those seeking to accomplish a variety of things. It is sometimes deployed in rightwing and populist politics by those who long for the 'good old days' when life seemed easier, safer, and less threatening. But social cohesion can also be used by those who fear the consequences of excessively marketised visions of the future" (1998: 37).

\section{Social Cohesion between Academia and Institutions: Comparing Visions}

There is not a common and shared vision about what social cohesion means (Addeo and Bottoni 2014, Di Franco 2014, Addeo and Bottoni 2016). Being a multidimensional concept, social cohesion includes different subdimensions that, in some conceptualization, overlap with other concepts such as quality of life, social capital, social integration, etc.

It is possible to identify two approaches of social cohesion with different aims and interests: the institutional and the academic approach. The institutions are interested in the concept of cohesion just for policy purposes. Having different aims, institutions provide different conceptualizations depending on the policy objective to be pursued.

According to the OECD, social cohesion is something related to the material well-being: a utilitarian element that would work as a guarantee against the rapid and unpleasant changes of the globalized economy. Social cohesion, as an antidote to the flexibility of the global market, would allow overcoming the crisis (Addeo and Bottoni 2014: 49). For the EU and the EC, social cohesion would be the mean for reducing inequalities among citizens, social exclusion and unemployment. This concept covers both the economic sphere and social inequality. In addition to the EU, OECD and EC definitions, the World Bank considers social cohesion as the union of two dimensions: inclusiveness of communities and institutional room-for-maneuver, both necessary for the growth of a society, even from an economic perspective. According to the World Bank, in fact, there is a direct link between social cohesion and macroeconomic performance. Thinking about social cohesion, we cannot consider just the sense of belonging to a community, a common feeling 
or a common purpose. It is necessary to add a component of macro policy because "the quality of the institutions and governments has a fundamental impact on the ability that societies have in finding solutions to their problems, and in ensuring that these solutions are the result of a negotiation that will benefit the community. The quality of institutions affects the environment in which individuals are acting, determining also the set of opportunities in which they can move" (Addeo and Bottoni 2014: 52). We find the Jenson's proposal (1998) among the most interesting proposals in the so-called academic approach. Jenson, from the University of Montreal, carried out a study for the Canadian Policy Research Networks. The author argued that social cohesion expresses the language of those who regret a past when society was cohesive, "in these discussions, the focus is often on 'deterioration.' In a general way, the concept of social cohesion assumes there are certain societal level conditions and processes that characterize a well-functioning society and that at this time these conditions may no longer be satisfied [...] it is important to acknowledge where conversations about social cohesion originate. They take place among those who sense an absence of some sort. "It is the vocabulary of those who judge the things are not going well" (Jenson 1998: 3).

Jenson's proposal started from the analysis of official documents coming from the Canadian and French Government, from the OECD, and the Club of Rome.

Through the analysis of these four documents, Jenson identifies five dimensions of the social cohesion:

- Belonging/isolation

- Insertion/exclusion

- Participation/passivity

- Recognition/rejection

- Legitimacy/illegitimacy

The first dimension concerns the sharing of values and the existence of a common identity. All the documents show an aspect common trait defined by Jenson as "belonging".

The second aspect refers to exclusion, in particular the exclusion from some institutions that prevents individuals from the enjoyment of a full citizenship. Such institutions could be economic (the labor market that generates economic integration); social (the welfare system that generates social integration); or community (such as family or neighborhood that generate interpersonal integration).

The third dimension refers to participation, commitment and involvement in the democratic and politic life of a country or a community.

The fourth dimension concerns the respect for diversity and rejection of all types of discrimination.

At last, there is the private and public institutions legitimacy and their role in conflict resolutions. 
Bernard (1999) identified a gap in this proposal and he added another dimension to the Jenson's model (Table 1). By distinguishing these dimensions based on their formal and substantial character (social representations) and "substantial" (behavior), Bernard added the dimension "Equality / Inequality" that is related to the economic / substantive sphere.

Table 1. Typology of Social Cohesion Dimensions

\begin{tabular}{|l|l|l|}
\hline $\begin{array}{l}\text { Spheres of Activity } \\
\text { Relation }\end{array}$ & \multicolumn{1}{c|}{ Formal } & \multicolumn{1}{c|}{ Substantial } \\
\hline Economic & Insertion / Exclusion & Equality / Inequality \\
\hline Political & Legitimacy/ Illegitimacy & Participation / Passivity \\
\hline Sociocultural & Recognition / Rejection & Belonging / Isolation \\
\hline
\end{tabular}

Source: Bernard 1999.

Reducing inequalities among individuals becomes one of the two pillars of the further conceptualization proposed by Berger-Schmitt (2002).

This conceptualization divides the concept of social cohesion in two macrodimensions that can be also interpreted as policy objectives:

1. Inequality: reducing the differences among citizens.

2. Social Capital: increasing and strengthening social bonds.

For each macro-dimension, it is possible to identity three sub-dimensions:

1. Inequality:

a. Disparities between regions or states

b. Equal opportunities between different social subjects

c. Social exclusion

2. Social Capital:

a. Relationships within the primary groups and associations

b. Quality of relationships

c. Quality of institutions

The first three sub-dimensions refer, respectively, to reducing inequality among the different European areas, strengthening equal opportunities, reducing every type of discrimination, and, finally, reducing social exclusion to be understood as fighting against poverty.

The latter three sub-dimensions refers to strengthening relationships within primary groups and associations, increasing the quality of these relations and, finally, the quality of democratic institutions in terms of efficiency, effectiveness, reliability, credibility and stability.

The contribution provided by Chan et al. (2006) shows a different perspective. According to these authors, cohesion can be defined as "a state of affairs concerning both the vertical and the horizontal interactions among members of society as characterized by a set of attitudes and norms that 
includes trust, a sense of belonging and the willingness to participate and help, as well as their behavioral manifestations" (2006: 290).

By formulating the concept of social cohesion, Chan et al. identify two dimensions: one horizontal, referring to cohesion within civil society, and another vertical, related to vertical relationships within society. Moreover, the authors add two elements: the first, subjective, regarding individuals attitudes, the second, objective that refers to behaviours. By crossing these four dimensions it is possible to derive a typology (Table 2). In the table, for each of the four types, indicators are shown.

Table 2. Dimensions and Indicators of Social Cohesion

\begin{tabular}{|l|l|l|}
\hline & \multicolumn{1}{|c|}{ Horizontal } & \multicolumn{1}{c|}{ Vertical } \\
\hline Subjective & $\begin{array}{l}\text { Level of trust } \\
\text { Cooperation will }\end{array}$ & $\begin{array}{l}\text { Trust in public figures } \\
\text { Trust in institutions }\end{array}$ \\
\hline Objective & $\begin{array}{l}\text { Social Participation } \\
\text { Volontary work }\end{array}$ & Political participation \\
\hline
\end{tabular}

Source: Chan et al. 2006.

The most interesting element of Chan's formulation is the total absence of the economic dimension. Differently from other definitions, the economic dimension is not considered as part of social cohesion, but rather as an explanatory factor.

This brief literature review about social cohesion highlights that there is no agreement among its various definitions. There are authors who favour aspects related to the cultural dimension such as the shared norms, values and a sense of belonging to the community (Jenson 1998). There are other authors, instead, who consider more important the economic dimension in terms of reducing inequality among citizens (Berger-Schmitt 2002) and still others who do not consider this dimension as part of social cohesion eliminating it altogether (Chan et al. 2006).

\section{An Alternative Proposal for Operationalizing Social Cohesion}

In this section, the authors show a theoretical and practical proposal aimed at measuring the concept of Social Cohesion among European countries through an index created with multivariate analysis techniques. Our goal is not to establish a universal definition of the concept, but rather to build a synthetic index of social cohesion that can be easily reproducible by other researchers and act as tool to measure the cohesion level within the European Union.

Starting from the literature about social cohesion, the concept has been developed into six sub-dimensions (Addeo and Bottoni 2016), shown in the following conceptual map (Figure 1): 
Figure 1. Conceptual Map

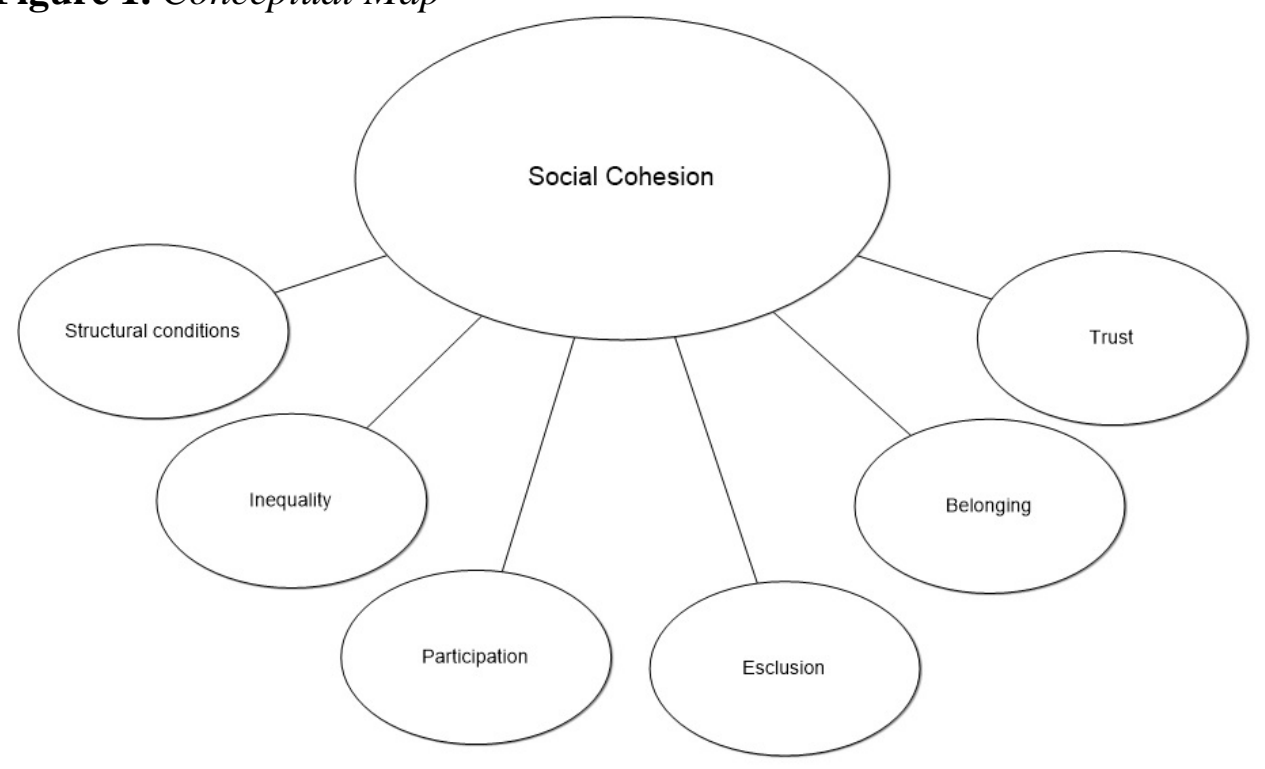

In detail, dimensions are defined as follows:

1. Structural conditions. It refers to the structure of the labour market. Several authors (Ritzen 2000, Stevens and Michalski 1994), as well as institutional bodies (OECD, EU), have identified unemployment as one of the main elements of social fabric breaking, as well as social exclusion. Among the key indicators of this dimension there is certainly the long-term unemployment (rather than the unemployment rate considered in itself) which has an effect not only in terms of income reduction, but also in terms of social status decline, interpersonal relationships and self-esteem, which in the long term generate exclusion and lead individuals to un-employability. Ritzen (2000) states that "the unemployed are typically excluded from mainstream economic activity and are, therefore, denied access to property and credit. In most of the developing world, especially Africa, long-term unemployment has rendered many people unemployable. [...] Unemployment does more than deprive one of an income, in most societies unemployment greatly reduces one's status in society";

2. Inequality. Many authors who have dealt with social cohesion (BergerSchmitt and Noll 2000, Berger-Schmitt 2002, Noll 2002, Bernard 1999) have recognized this dimension as fundamental. In our perspective, following the indications of Berger-Schmitt (2002), this dimension has been further divided into "income inequality", "gender inequality", "generation inequality", "nationality inequality";

3. Participation. This dimension refers to commitment, involvement and participation in the democratic and politic life of the country and the community of the citizens. Moreover, it also measures civic engagement that benefits the community, including the third sector, and promotes the development of social cohesion; 
4. Exclusion. This dimension, together with inequality, is central to the definition of the concept of social cohesion: there cannot be cohesion if society produces social exclusion. This concept refers to the expulsion from certain institutions that prevents individuals from fully participating and enjoying a full citizenship. In our framework, the concept has been divided into two further sub-dimensions, "economic exclusion" regarding the material deprivation and "social exclusion" which covers elements such as early school leaving;

5. Belonging, shared values, recognition of differences. This dimension is crucial in the Canadian idea of social cohesion. Jenson (1998) defines "belonging" as one of the five basic dimensions of social cohesion. Some authors identify this dimension directly with the concept of social cohesion. Kearns and Forrest (2000) state that "a socially cohesive society is one in which the members share common values which enable them to identify common aims and objectives, and share a common set of moral principles and codes of behavior through which to conduct their relations with one another". Regarding the differences recognition, it is possible to assert that "diversity" is a trademark of the global society. Jenson recognizes the conflict over access to "resources" as inevitable in a society like ours. To this purpose, Jenson lists a number of possible quarrels that may occur in a globalized context, such as the "over definitions of national identity; over the relation between religion and the modern state; over the capacity of the society to adapt to other cultures; over the practical and moral scope of the welfare state; over the applicability of Western notions of human rights everywhere; over the public and legal status of issues of personal morality; and over the role of civil society as against the institutions of the state" (Jenson 1998: 16). Conflicts should not be fixed up through an attempt of homogenization, but the differences can be rather seen as a virtue that leads to pluralism. Sharing values and recognizing diversity may seem conflicting goals. Speaking about shared values, while having to respect differences in a global society, might be seen as a contradiction. However, threats to social cohesion do not come from diversity within society (or from its pluralism). Diversity becomes a threat when the differences are the basis for creating discrimination and inequality;

6. Trust is an essential element of social cohesion. Interpersonal trust, especially in studies about social capital, is referred to as a fundamental feature for a functioning social system. High levels of trust would generate virtuous circles and promote the economic growth of a society. In addition to interpersonal trust, our work also took into account people having trust in institutions. These people play a key role in mediating conflicts that can arise within a society and, above all, through their actions, they are able to shape and modify the environment in which citizens are acting. 


\section{Measuring Social Cohesion and Other Relevant Related Concepts}

Our main goal is to operationalize the concept of Social Cohesion, taking into account not only economic factors, but also other fundamental dimensions that define the Welfare of a country, such as active citizenship, trust, shared values, integration.

The main research goal could be expressed in this way:

R1: To create a reliable and reproducible Social Cohesion Index

Starting from the main research aim, other relevant objectives were pursued, and then translated into the following sub-research questions:

Sub-R1: What is the relationship between economic indicators and Social Cohesion?

Sub-R2: What is the relationship between objective well-being and Social Cohesion?

Sub-R3: What is the relationship between quality of institution of a Country and Social Cohesion?

Sub-R4: What is the relationship between subjective satisfaction of people and Social Cohesion?

In order to answer to our sub-research questions, we have built four indices up concerning these four dimensions: Social Cohesion, Objective Wellbeing, Quality of Institution and Subjective Satisfaction. More specifically, the dimensions were measured by creating composite indices from a set of 122 indicators coming from several official datasets: Eurostat, for the ecological data, while the survey data were collected from datasets such as GESIS Leibniz-Institute for the Social Sciences - Social Indicators Monitor (SIMon), Eurobarometer and European Value Survey.

The units of analysis are the 27 EU Member States.

In order to extract information from the 122 indicators set, we adopted a two-steps factor analysis (Di Franco and Marradi 2013): first, four factors were extracted from the set; then, the factor analysis was applied again to each factor separately (i.e. only to the variables with the highest factor loadings were chosen). In other words, instead of extracting the general factorial structure and saving the resulting factorial scores, following Di Franco and Marradi's proposal, we refined each latent factor by applying a single factor analysis to each of them, and then removing those variables not strictly connected to the concept.

After the two-steps factor analysis, all the variables composing the indices were standardized to have a range from 0 to 100 and then summed ${ }^{1}$.

This procedure led to create four indices: Social Cohesion Index (SCI), Objective Well-being Index (OWI), Institutions' Quality Index (IQI), Subjective Satisfaction Index (SSI), and, as summary a of the previous four

\footnotetext{
${ }^{1}$ The semantic polarity of some variables was inverted to create indices that are more readable.
} 
indices we have also created an index named General Quality of the States Index (GQSI).

The Social Cohesion Index - SCI - (75\% of the variance explained) is represented by the following variables (see Table 3 for the factor loadings):

- Trust in Institutions

- Severely materially deprived people

- Feeling left out of society

- Interpersonal Trust

- Long-term unemployment

- Inequality of income distribution

- Low reading literacy performance of pupils

- Share of 15-year-old pupils who are at level 1 or below of the PISA combined reading literacy scale

- Approval of Gender Equality of Employment Opportunities

- Ratio of Women and Men Employed in an Influential Occupational Position

- Average turnout at the polls

This set of variables covers all the dimensions of the social cohesion concept identified in the concept map. The SCI mean scores were calculated for each country (see Figure 2).

Table 3. Factor Loadings of the Variables Used for the Social Cohesion Index

\begin{tabular}{|l|c|}
\hline Variables & Loadings \\
\hline Trust in Institutions educations system-justice-police-health care &,- 8703 \\
\hline Severely materially deprived people \% 4 items or more 2010 &, 855 \\
\hline Feeling left out of society 0 100 &, 828 \\
\hline Interpersonal Trust 2008 &,- 702 \\
\hline Long-term unemployment \% 15-64 2011 &, 694 \\
\hline Inequality of income distribution S80-S20 income quintile share ratio 2010 &, 628 \\
\hline $\begin{array}{l}\text { Low reading literacy performance of pupils - Share of 15-year-old pupils } \\
\text { who are at level 1 or below of the PISA combined reading literacy scale } \\
\text { 2009 }\end{array}$ &, 621 \\
\hline $\begin{array}{l}\text { Approval of Gender Equality of Employment Opportunities 2008 } \\
\text { Ratio of Women and Men Employed in an Influential Occupational } \\
\text { Position 2010 }\end{array}$ &,- 604 \\
\hline Average turnout at the polls (1990-2010) &, 567 \\
\hline
\end{tabular}

KMO $=0.798 ;$ Bartlett Test $=\mathrm{p}<.000$

The $27 \mathrm{EU}$ member states could be grouped in three clusters according to their score on the Social Cohesion Index. The first group, with the highest mean values on SCI, gathers Scandinavian Nations (Denmark, Sweden, Finland) along with Netherlands, Luxembourg, Cyprus, Austria, Malta and Belgium. The medium SCI scores group collects Slovenia, Germany, France, Spain, Czech Republic, Estonia, Ireland and England. Third group includes EU member states with low scores: Portugal, Greece, Italy, Poland, Hungary, Slovakia, Latvia, Romania, Lithuania and Bulgaria. 
Figure 2. Social Cohesion in Europe (Mean Values on SCI)

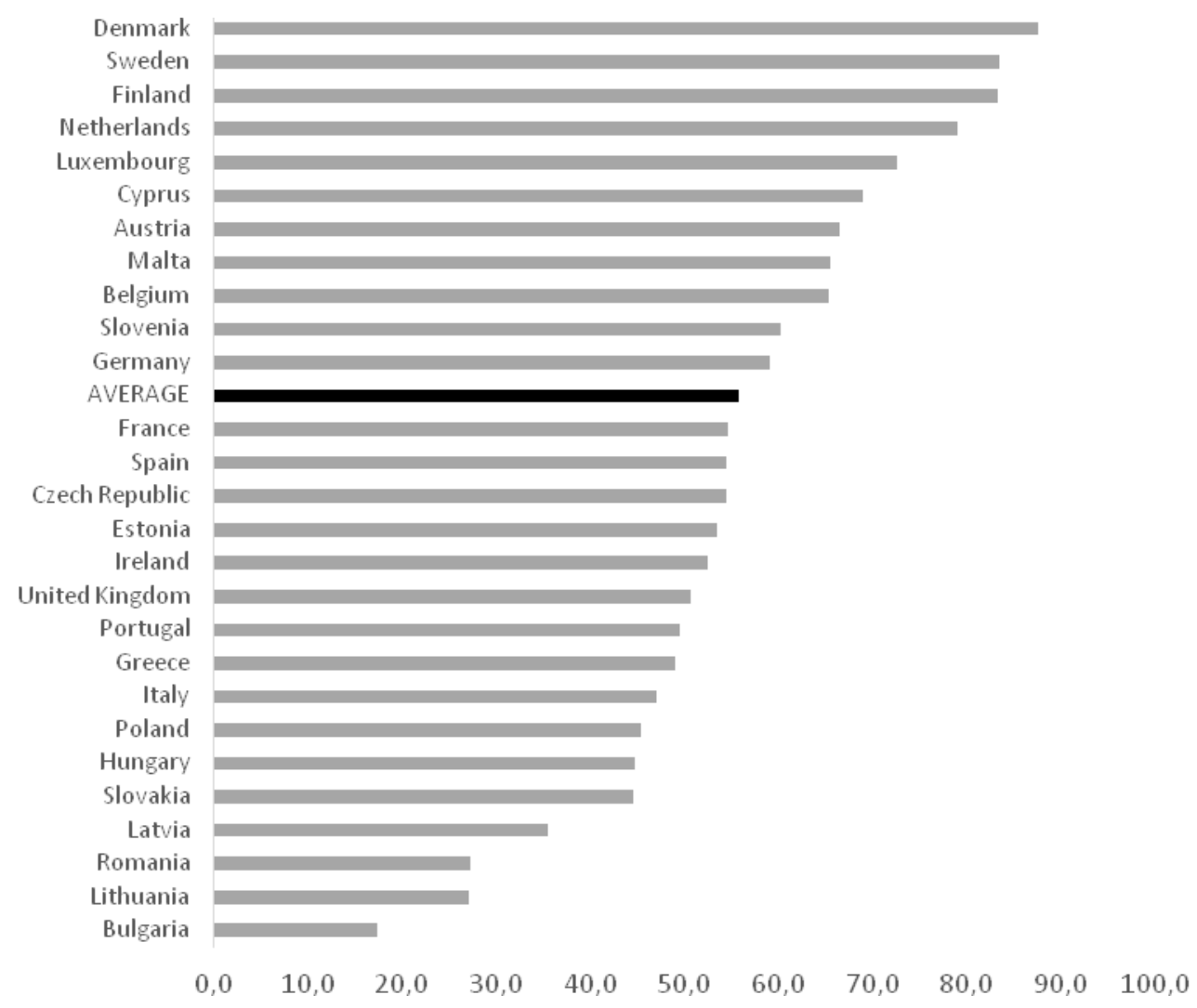

Objective Wellbeing Index (72\% of total variance) comprises ten variables: Overcrowding rate, Median equalized net income, Standardized death rate, Final consumption expenditure of households in euro per inhabitant expectancy, Life expectancy, Average number of rooms per person, GDP per capita, Share of total population having neither a bath, nor a shower in their dwelling, Infant mortality rate and Employment rate (Table 4).

Table 4. Factor Loadings of the Variables Used for the Objective Wellbeing Index

\begin{tabular}{|l|c|}
\hline \multicolumn{1}{|c|}{ Variables } & Loadings \\
\hline Overcrowding rate \% 2010 & -.941 \\
\hline Median equivalised net income 2010 & .933 \\
\hline Standardised death rate (per 100,000 inhabitants) all causes of death 2009 & -.932 \\
\hline Final consumption expenditure of households euro per inhabitant 2010 & .932 \\
\hline Life expectancy 2010 & .912 \\
\hline Average number of rooms per person 2010 & .886 \\
\hline GDP per capita 2010 & .834 \\
\hline Share of total population having neither a bath, nor a shower in their & -.769 \\
\hline dwelling 2010 & -.721 \\
\hline Infant mortality rate 2010 & .558 \\
\hline Employment rate 2011 & \\
\hline
\end{tabular}

$\mathrm{KMO}=0.749 ;$ Bartlett Test $=\mathrm{p}<.000$ 
With reference to the quality institutions dimension, two-steps factor analysis leads to the extraction of one factor (75\% variance explained) composed of five variables (Gross domestic expenditure on R\&D, Expenditure on social protection euro, E-government usage, Expenditure on social protection and Total public expenditure on education).

The index was named "Quality of Institutions Index" (see Table 5).

Table 5. Factor Loadings of the Variables Used for the Quality of Institutions Index

\begin{tabular}{|l|c|}
\hline \multicolumn{1}{|c|}{ Variables } & Loadings \\
\hline Gross domestic expenditure on R\&D \% GDP 2010 & .889 \\
\hline Expenditure on social protection euro per inhabitant 2009 & .874 \\
\hline E-government usage by individuals \% 2010 & .862 \\
\hline Expenditure on social protection \% GDP 2009 & .838 \\
\hline $\begin{array}{l}\text { Total public expenditure on education as \% of GDP, for all levels of } \\
\text { education combined 2009 }\end{array}$ & .708 \\
\hline
\end{tabular}

$\mathrm{KMO}=0.712 ;$ Bartlett Test $=\mathrm{p}<.000$

The latent factor extracted ( $75 \%$ of variance explained) represents the Subjective Wellbeing Index and includes five variables: Satisfaction with way of life, Happiness, General fear of crime and Subjective Poverty Risk (see Table 6). All these variables, in spite of all the previous ones from Eurostat, were collected with surveys (Gesis, Eurobarometer and European Value Survey).

Table 6. Factor Loadings of the Variables Used for the Subjective Wellbeing Index

\begin{tabular}{|l|c|}
\hline Variables & Loadings \\
\hline Satisfaction with Neighbourhood 2006 & .936 \\
\hline Satisfaction with Way of Life 2009 & .928 \\
\hline Happiness 2008 & .898 \\
\hline General Fear of Crime 2006 & -.837 \\
\hline Subjective Poverty Risk 2006 & -.784 \\
\hline
\end{tabular}

$\mathrm{KMO}=0.873 ;$ Bartlett Test $=\mathrm{p}<.000$

To address the four sub-research questions stated at the beginning of this paragraph, we performed a correlation analysis (Table 7).

The Social Cohesion Index is highly correlated with all the indices (Table $6)$. All the Pearson's correlation coefficients are significant $(p<0,001)$ ranging from .91 for Subjective Wellbeing $(\mathrm{R}$ squared $=0.82)$ to .83 Objective Wellbeing $(\mathrm{R}$ square $=.69)$, with the coefficient for Quality of Institutions that is equal to .85 .

It can be said that there are strong relationships among all the indices. However, these relationships could not be interpreted in a deterministic way. Indeed, it is not possible to say whether an index is the cause or the effect of another one.

With reference to Objective Wellbeing, the results are in line with those scholars (Ritzen 2000) stating that social cohesion is related to the 
macroeconomic performance of a country. In conclusion, higher levels of Social Cohesion identify those Countries with high levels of economic wellbeing, Subjective Wellbeing and Quality of Institutions although nothing can be said about the direction of these relationships.

Table 7. Correlation Matrix among SCI and the Other Indices

\begin{tabular}{|l|l|c|c|}
\hline \multicolumn{2}{|l|}{} & $\begin{array}{c}\text { Social Cohesion } \\
\text { Index }\end{array}$ & $\begin{array}{l}\text { R } \\
\text { squared }\end{array}$ \\
\hline \multirow{2}{*}{$\begin{array}{l}\text { Objective Wellbeing } \\
\text { Index }\end{array}$} & $\begin{array}{l}\text { Pearson's } \\
\text { Correlation }\end{array}$ & 0.834 & 0.69 \\
\cline { 2 - 4 } $\begin{array}{l}\text { Qig. (2-tails) } \\
\text { Index }\end{array}$ & $\begin{array}{l}\text { Pearson's } \\
\text { Correlation }\end{array}$ & 0.854 & 0.72 \\
\cline { 2 - 4 } & Sig. (2-tails) & 0 & \\
\hline \multirow{2}{*}{$\begin{array}{l}\text { Subjective Wellbeing } \\
\text { Index }\end{array}$} & $\begin{array}{l}\text { Pearson's } \\
\text { Correlation }\end{array}$ & 0.908 & 0.82 \\
\cline { 2 - 4 } & Sig. (2-tails) & 0 & \\
\hline
\end{tabular}

Going beyond the main goal of our research, we built a general index to summarize all the information contained in the four indices discussed above. The index, created with a single factor analysis technique, was named Overall Country Quality $(\mathrm{COQ})^{2}$. The COQ index sums up all the dimensions regarding Social Cohesion, Objective Wellbeing, the Quality of the Institutions and Subjective Wellbeing. The higher is the COQ score of a Country, the better are the life conditions of its citizens. Indeed, in the countries with a high COQ score, people can experience higher social cohesion, higher economic wellbeing, higher life expectancy, and more equality, higher levels of happiness, satisfaction and quality of Institutions.

The next figure shows the ranking of the $27 \mathrm{EU}$ member states according to COQ index (Figure 3).

The first three positions are held by Scandinavian countries: Denmark, Sweden and Finland, followed by the Netherlands and Luxembourg (whose score is affected by its excellent economic conditions). These results are in line with Berger-Schmitt study on life conditions in European countries: "for the majority of the indicators, the Nordic countries, Luxembourg and the Netherlands prove to be the countries with the best situation" (2002: 724). If we set the average as a benchmark, Mediterranean countries have a score slightly higher or slightly lower than the general mean (except Greece). The reasons why Mediterranean countries are placed in this way differ from Country to Country: in Italy, for example, good economic performances are negatively counterbalanced by low performances on the aspects like social cohesion, quality of institutions and Subjective Wellbeing.

\footnotetext{
${ }^{2}$ The scores were normalized in a range from 0 to 1
} 
Figure 3. Overall Country Quality

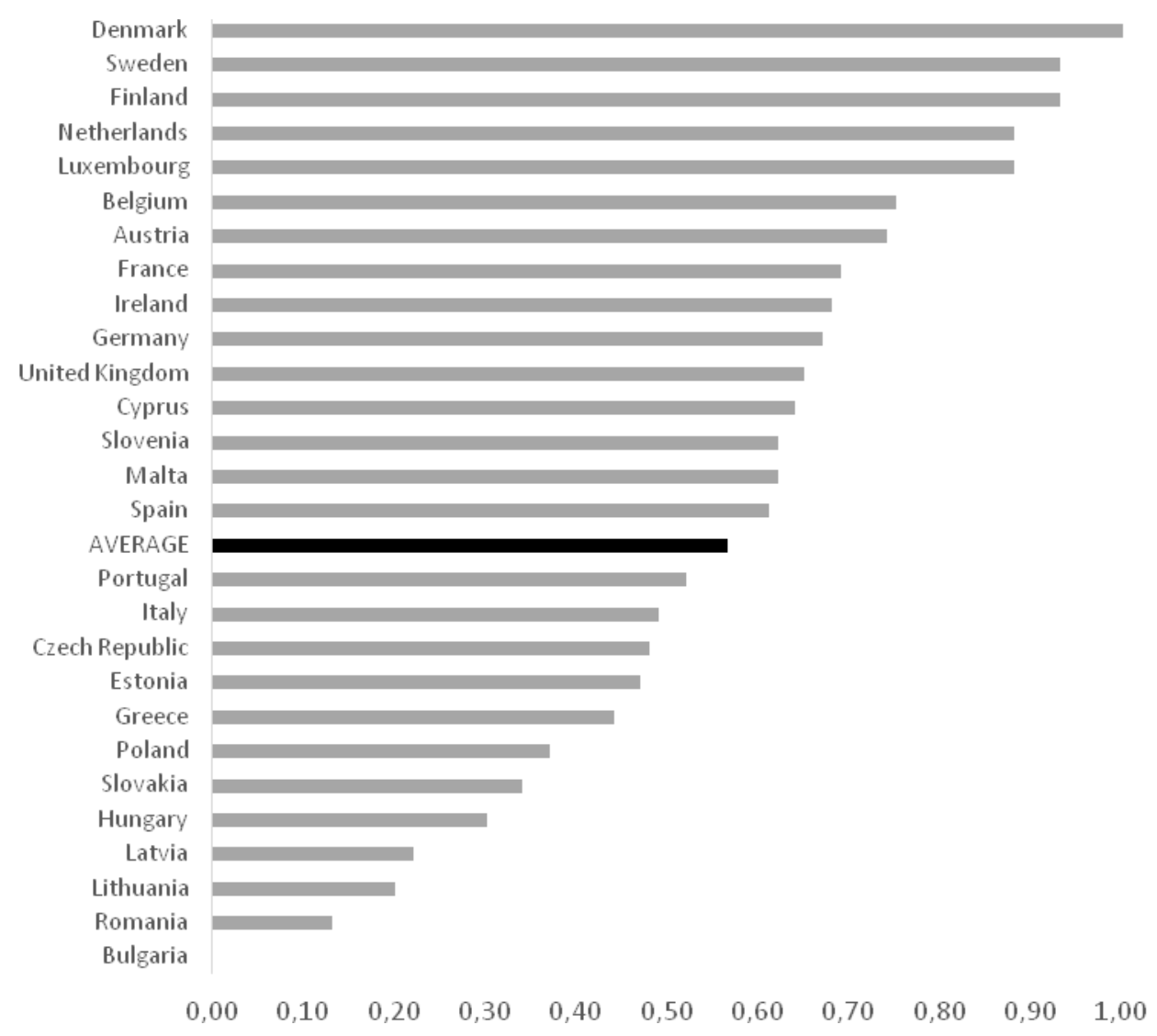

\section{Conclusions and Further Research}

Our analysis shows symmetric and bidirectional statistical relationships among the four dimensions; so we think that a circular model rather than a linear one could best represent these results (see Figure 4).

This model is relevant to policy making: the bi-directionality allows the creation of virtuous circles among the different domains of society improving the general performances of a Country.

There is a strict circular tie among the four dimensions: they influence each other reinforcing mutually.

Measuring these dimensions on a regular basis could definitely help policy makers evaluate the outcomes of their actions improving the effectiveness of government policies. 
Figure 4. Quality of Countries: Circular Model

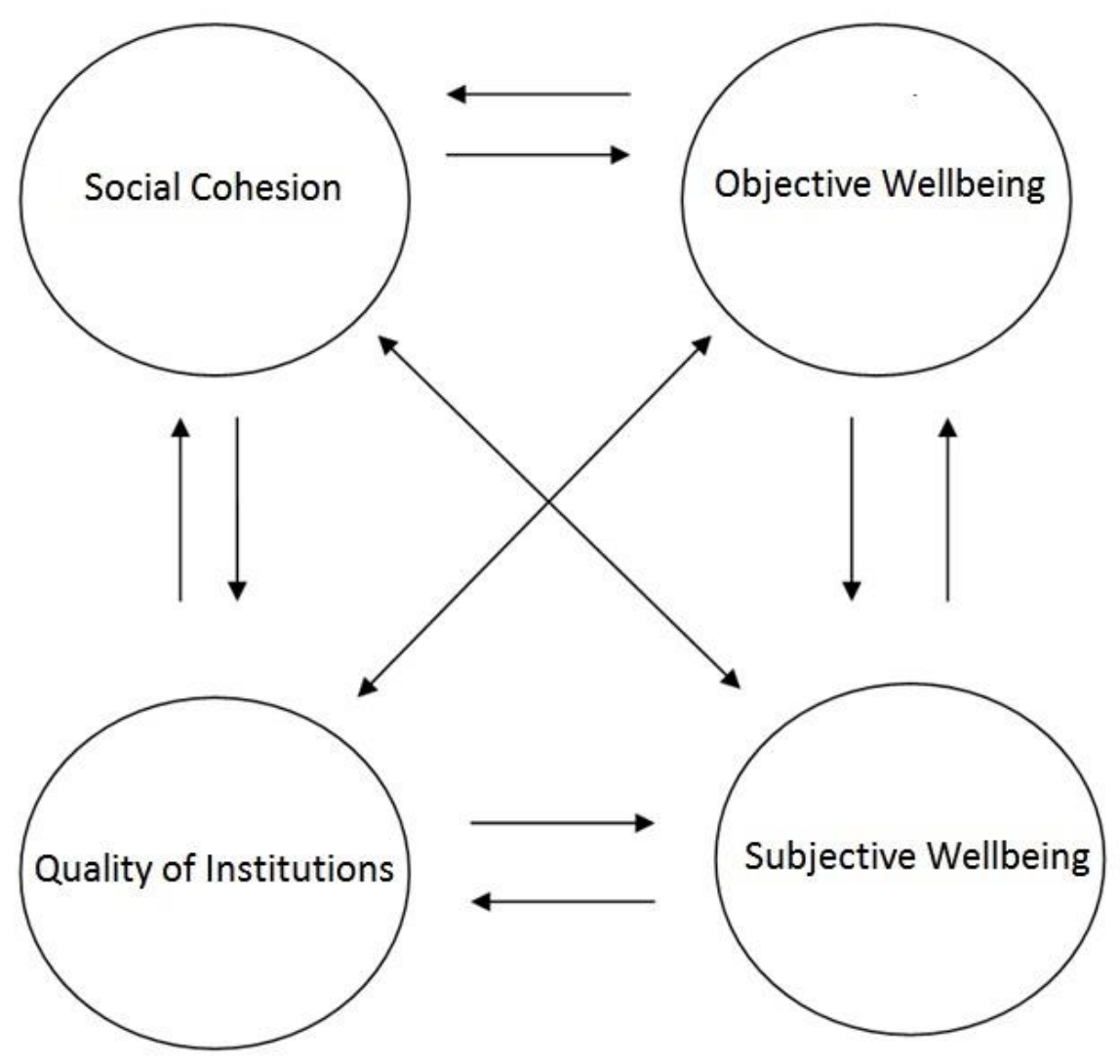

From a substantial point of view, the overall quality index shows that European countries are growing at different speeds, with the Mediterranean ones being around a potentially dangerous central position, with each country having its own peculiar strengths and weaknesses that could help explaining their score in the chart. However, all the big Mediterranean countries have in common a low score on the Social Cohesion index; this means that improving the Social Cohesion is a crucial step to enhancing the quality of a country. In fact, a deeper analysis of the Overall Country Quality index results suggest that many European governments should start tackling the inner crisis using a wider perspective rather than merely focusing on economic indicators; for example, by including social cohesion policies to help the overall development of their countries.

The next steps of our research will be to refine the operational definition of the analyzed concepts (Figure 4) and, above all, to implement a longitudinal perspective. The first step will lead to improve the conceptual framework of the research, and, subsequently, to refine the set of indicators to analyze with the multivariate approach. The second step is necessary to understand the evolution of Social Cohesion over time. To this purpose, we will also take into account the effects on Social Cohesion of economic, political and social changes that occurred over the past 15 years, such as the 2008 financial crisis, 
the political instability, or the impacts of some crucial referendum (i.e. the Brexit).

\section{References}

Addeo F (2008) È normale la curva normale? Genesi e sviluppo di un mito. [Is it normal the normal curve? Birth and raise of a myth]. Acireale-Roma: Bonanno.

Addeo F, Bottoni G (2014) Concetti e misure della coesione sociale [Concepts and measure of social cohesion]. In Il poliedro coesione sociale. Analisi teorica ed empirica di un concetto sociologico, G Di Franco (Ed). Milano: FrancoAngeli.

Addeo F, Bottoni G (2016) Coesione Sociale e regimi di welfare. Un'indagine empirica sugli Stati dell'Unione Europea [Social cohesion and welfare regimes, an empirical research on EU member states]. In Nel Complesso Mondo del Welfare, M Del Frono (Ed). Milano: FrancoAngeli.

Beauvais C, Jenson J (2002) Social cohesion: Updating the state of the research. CPRN Discussion Paper, No. F|22. Ottawa: Canadian Policy Research Networks.

Berger-Schmitt R (2002) Considering social cohesion in quality of life assessments: concept and measurement. Social Indicators Research 58: 403-428.

Berger-Schmitt R, Noll HH (2000) Conceptual framework and structure of a European system of social indicators. EuReporting Working Paper No. 9, Centre for Survey Research.

Bernard P (1999) Social cohesion: A dialectical critique of a quasi-concept. Paper SRA-491, Strategic Research and Analysis Directorate Ottawa: Department of Canadian Heritage.

Campbell A (1981) The sense of well-being in America. New York: McGraw-Hill.

Campbell A, Converse PE, Rodgers WL (1976) The quality of American life: perceptions, evaluations, and satisfactions. New York: Russell Sage Foundation.

Chan J, To HP, Chan E (2006) Reconsidering social cohesion: Developing a definition and analytical framework for empirical research. Social Indicators Research 75(2): 273-302.

Clark DA (2008) The capability approach: its development, critiques and recent advances. In Development Studies II, R Ghosh, KR Gupta, Prasenjit Maiti (Eds). New Delhi: Atlantic Books and Distributors.

Di Franco G (Ed) (2014) Il poliedro coesione sociale. Analisi teorica ed empirica di un concetto sociologico [The social cohesion polyhedron. theoretical and empirical analysis of a sociological concept]. Milano: FrancoAngeli.

Di Franco G (1989) Qualità della vita: dai modelli alle ricerche empiriche, [Quality of life: from models to research]. In Dimensioni sociali e territoriali della qualità della vita [Social and Territorial Dimensions of the Quality of Life], Vergati S (ed). Roma: La Goliardica.

Di Franco G, Marradi A (2003) Analisi fattoriale e analisi in componenti principali [Factor analysis and principal component analysis]. Acireale-Roma: Bonanno.

Diener E, Diener C (1995) The wealth of nations revisited: Income and quality of life. Social Indicators Research 36(3): 275-286.

Diener E, Diener M, Diener C (1995) Factors Predicting the Subjective Well-Being of Nations. Journal of Personality and Social Psychology 69(5): 851-864.

Diener E, Suh E (1997) Measuring quality of life: Economic, social, and subjective indicators. Social Indicators Research 40(1-2): 189-216. 
Durkheim E (1893) De la division du travail social: étude sur l-organisation des sociétés supérieures [From the division of social work: study on the organization of higher societies]. Paris: Presses Universitaires de France.

Inglehart R (1977) The silent revolution. Princeton: Princeton University Press.

Jeannotte MS (2003) Social cohesion: Insights from Canadian research. International Comparative Research. Québec: Department of Canadian Heritage, Gatineau.

Jenson J (1998) Mapping social cohesion: The state of Canadian research. Canadian Policy Research Network (CPRN) Study No. F103.

Kearns A, Forrest R (2000) Social cohesion and multilevel urban governance. Urban Studies 37(5-6): 995-1017.

Noll H (2002) Toward a European system of social indicators: theoretical framework and system architecture. In Assessing Quality of Life and Living Conditions to Guide (Social Indicators Research Series), MR Hagerty, J Vogel, V Møller (Eds). Berlin: Springer.

Parsons T (1937) The structure of social action. New York: McGraw Hill.

Ritzen J (2000) Social cohesion, public policy, and economic growth: implications for OECD countries. Keynote address presented at the Symposium on the Contribution of Human and Social Capital to Sustained Economic Growth and Well Being, March 20. Quebec City.

Sen A (1985) Commodities and capabilities. Oxford: Elsevier Science Publishers.

Stevens B, Michalski W (1994) Long-term prospects for work and social cohesion. In OCDE Societies in Transition: the Future of Work and Leisure, B Stevens, W Michalski (Eds). Paris: OECD.

Stiglitz J E, Sen A, Fitoussi JP (2009) Report by the commission on the measurement of economic performance and social progress. Commission on the Measurement of Economic Performance and Social Progress. 
